\title{
Wine and music (II): can you taste the music? Modulating the experience of wine through music and sound
}

\author{
Charles Spence ${ }^{1,2^{*}}$ and Qian (Janice) Wang ${ }^{1}$
}

\begin{abstract}
A growing body of scientific evidence now shows that what people taste when evaluating a wine, and how much they enjoy the experience, can be influenced by the music that happens to be playing at the same time. It has long been known that what we hear can influence the hedonic aspects of tasting. However, what the latest research now shows is that by playing the "right" music one can also impact specific sensory-discriminative aspects of tasting as well. Music has been shown to influence the perceived acidity, sweetness, fruitiness, astringency, and length of wine. We argue against an account of such results in terms of synaesthesia, or "oenesthesia," as some have chosen to call it. Instead, we suggest that attention, directed via the crossmodal correspondences that exist between sound and taste (in the popular meaning of the term, i.e., flavor), can modify (perhaps enhance, or certainly highlight when attended, or suppress when unattended) certain elements in the complex tasting experience that is drinking wine. We also highlight the likely role played by any change in the mood or emotional state of the person listening to the music on taste/aroma perception as well. Finally, we highlight how the crossmodal masking of sweetness perception may come into effect if the music happens to be too loud (a form of crossmodal sensory masking). Taken together, the evidence reviewed here supports the claim that, strange though it may seem, what we hear (specifically in terms of music) really can change our perception of the taste of wine, not to mention how much we enjoy the experience. Several plausible mechanisms that may underlie such crossmodal effects are outlined.
\end{abstract}

Keywords: Wine, Music, Crossmodal correspondences, Multisensory, Emotion, Synaesthesia

\section{Review}

Can what we listen to change our perception of the taste of wine? That, at least, is the claim made by a number of researchers recently. Such claims, strange as they may seem, have often met with a healthy dose of skepticism from the general public and media at large: Just take the following, from Alice Jones, writing in The Independent newspaper, when she expressed doubt that the claim that "wine tastes better with music" would "stand up to scientific scrutiny." ([1], p. 51). On the other hand, we have powerful first-person reports documenting the sometimes transformative influence of the "right" music on the wine tasting experience. For instance, take the following from James John, Director of the Bath Wine

\footnotetext{
* Correspondence: charles.spence@psy.ox.ac.uk

${ }^{1}$ Crossmodal Research Laboratory, Oxford University, Oxford, UK

${ }^{2}$ Department of Experimental Psychology, University of Oxford, Oxford OX1 $3 \cup D, U K$
}

School, as representative. He says of the combination of Mozart's Laudate Dominum and Chardonnay: "[...] Just as the sonant complexity is doubled, the gustatory effects of ripe fruit on toasted vanilla explode on the palate and the appreciation of both is taken to an entirely new level" (quoted in [2]).

But what do the results of well-controlled scientific studies have to say on the matter? As highlighted in a recent review on the topic (see [3]), a growing body of peer-reviewed empirical research already shows that the pact on the wine tasting experience itself. After all, why should changing the music we hear influence our experience of the wine we taste? As we will see, the evidence 
reviewed in this article clearly demonstrates that the music we listen to really can change our experience of wine tasting. What is more, the latest research goes beyond the long line of research demonstrating an impact of the context, or environment, on the hedonic pleasure people get from drinking. If one gets the music right, one really can modify certain specific aspects of the wine tasting experience, such as the perceived sweetness and acidity, fruitiness, astringency, and length (cf. $[4,5]$, for evidence that changing the color of the lighting can also change the experience).

Here, we review the evidence demonstrating such crossmodal influences, before going on to look at what is currently known about the mechanisms that may underlie such effects. We argue against an account in terms of synaesthesia [6]. Instead, we develop an explanation that is based on the emerging literature on crossmodal correspondences and attention. Crossmodal correspondences are the surprising associations that we all share between features, attributes, and sensory dimensions in one sensory modality and the seemingly unrelated features, attributes, and sensory dimensions of experience in another modality $[7,8]$, such as between roundness and sweetness or brightness and pitch. Relevant here, a number of crossmodal correspondences between music (or musical attributes), on the one hand, and the taste, aroma/bouquet, mouthfeel, and/or flavors that are found in wine have been demonstrated in recent years [9-12]. Such correspondences between music and taste (i.e., flavor) may serve to direct the taster's attention to specific features in the wine, while listening to music. Alternatively, it might presumably be possible for a particular piece of music to be rated as going especially well with a given wine, and yet people might nevertheless still be able to isolate their experience of the wine without being influenced by what they hear. The intuition here has to be that if anyone can, the experts, wine makers etc., ought to be better able to isolate their tasting experience and ignore the music than the general public. But can they?

While a growing body of empirical evidence now demonstrates that music affects our perception and experience while drinking wine, unpacking the various mechanisms that may underlie such crossmodal effects is an altogether more challenging (and currently ongoing) endeavor. Crossmodal correspondences, the impact of any music-induced change in our mood or emotions, synaesthesia, sensation transference, and crossmodal masking, are just some of the more popular suggestions that have been put forward to explain what may be going on here (see Table 1). We will look in detail at the first two of these putative mechanisms later.

\section{Modifying the tasting experience with music}

At the outset, it is important to note that there are a number of ways in which what we hear could influence what we think about what we taste. There may, for example, be generalized effects of music, such that classical music may make people rate a wine as more expensive (cf. $[13,14]) .{ }^{1}$ It has been shown that ethnically appropriate music can help to bring out the ethnicity in a dish of food ([15-17]), and hence, possibly also the typicity [18] in wine too. Indeed, as Paul White ([19], p. 122) noted a few years ago, "Both wine and music have a capacity to pack themselves into neat little genres, each with distinct national and historic flavors." It would also seem reasonable to suggest that if we like the music, then we might be a little more likely to appreciate the wine as well-one can think of this as an example of "sensation transference" [20]; listening to music may put the listener in a certain mood or emotional state [21], either good or bad. This too might be expected to influence our perception and appreciation of wine [22, 23]. A growing body of scientific evidence also demonstrates that sounds that are too loud can lead to a crossmodal suppression of taste and alcohol perception (e.g., [24-26]; see [27] for a review). Finally here, one could imagine how even simply knowing that a particular piece of music had been chosen, or better still, composed, to go with a specific wine could exert a generalized uplift effect on one's multisensory tasting experience (cf. [28]).

Although there is a large and growing literature documenting the various ways in which what we hear, specifically music, influences our general experience and

Table 1 Summary of findings from scientific studies on the possible mechanisms underlying the auditory modulation of the winetasting experience

\begin{tabular}{lll}
\hline Mechanism & Explanation & Supporting research \\
\hline $\begin{array}{l}\text { Crossmodal } \\
\text { correspondences }\end{array}$ & $\begin{array}{l}\text { Correspondences between sound and taste draw attention to different } \\
\text { components in the wine }\end{array}$ & $\begin{array}{l}\text { Spence [68]; Van Ee et al. [82]; Chiou and Rich [78]; } \\
\text { Klapetek et al. [79] }\end{array}$ \\
$\begin{array}{l}\text { Emotion } \\
\text { Synaesthesia }\end{array}$ & $\begin{array}{l}\text { Music changes emotions, which in turn change the drinking experience } \\
\text { Sensation }\end{array}$ & $\begin{array}{l}\text { Pollatos et al. [90]; Heath et al. [91]; Smith [92] } \\
\text { transference }\end{array}$ \\
Crossmodal masking & People's feelings towards the music are transferred to the wine & Sachse-Weinart [6] \\
\hline
\end{tabular}


evaluation of food and drink (e.g., see [29, 30] for reviews), what we want to focus on here, specifically, is the question of whether music that in some way corresponds crossmodally (see [3] for a review), or matches, a wine can help to bring out specific sensory attributes in the tasting experience. ${ }^{2}$

\section{The impact of music on taste: assessing the evidence} Californian winemaker and wine consultant, Clark Smith, has conducted a number of tasting panels in which he claims to have evaluated 150 different wines while listening to around 250 songs. The aim, according to Smith, was "to find the harmonies and discordances" (cited in [31]; see also [22, 32]). Smith has observed how the flavors of the wines would sometimes change in the presence of the appropriate background music. Apparently, certain wines would be rated as "more delicious" when tasters were listening to one piece of music rather than another. While it seems highly unlikely that Smith could have conducted a fully crossed experimental design of all the wines and music selections to find the optimum pairings (that would have required tasting a total of 37,500 combinations), it is nevertheless still worth highlighting some of the music-wine combinations that Smith claims to work particularly well together (see Table 2).

Seminal empirical work on the impact of music on the wine tasting experience was conducted by Prof. Adrian North then at Herriot Watt University in Scotland ([34]). He offered a glass of red (Cabernet Sauvignon) or white wine (Chardonnay, both from Chile, and retailing at about $£ 10$ a bottle) to 250 university students (all under 25 years of age) in exchange for their thoughts concerning its taste. The students drank their wine while listening to one of four pieces of specially selected music or else drank in silence (thus, the participants were assigned to 1 of 10 conditions in this between-

Table 2 Wine and music pairings as recommended by Clark Smith

Wine and music pairing recommendations based on research by Clark Smith

Carneros Pinot Noir

"Eine Kleine Nachtmusik"-Mozart

Cabernet Sauvignon

"People are Strange"-The Doors, or Carmina Burana-Orff

Sutter Home White Zinfandel

"Milorganite Blues"-North Water Street Tavern Band

Glen Ellen Chardonnay

"California Girls"-The Beach Boys

Rombauer Carneros Chardonnay

"St Louis Blues-Ella Fitzgerald"

Table reprinted with permission from [33] participants design). The musical selections had been chosen to convey different meanings: Carmina Burana by Orff-"powerful and heavy"; Waltz of the Flowers from The Nutcracker by Tchaikovsky-"subtle and refined"; Just Can't Get Enough by Nouvelle Vague-"zingy and refreshing"; and Slow Breakdown by Michael Brook-"mellow and soft." On emptying their glass, the students then had to rate the wine by giving it a score from $0-10$ on each of 4 rating scales: "powerful and heavy," "subtle and refined," "zingy and refreshing," and "mellow and soft." A score of 0 indicated that "The wine definitely does not have this characteristic." A score of 10 , on the other hand, indicated that "The wine definitely does have this characteristic."

The results (see Table 3) revealed that the two wines were judged as tasting significantly more powerful/heavy by those who had listened to the "heavy" music. Meanwhile, the wines were rated as tasting $40 \%$ more zingy/ fresh by those listening to the Nouvelle Vague track. ${ }^{3}$ A similar pattern of results was also reported for those listening to the mellow/soft and subtle/refined music selections. Based on these results, Montes wines suggested a number of musical selections to match different grapes (see Table 4; recommendations taken from [35]). However, while the results of North's study are clear enough, the most appropriate interpretation of the underlying cause of these crossmodal effects has been debated by researchers [36]. Here, it is perhaps informative, not to mention surprising, to note that the music had exactly the same effect on both the white and red wines (while a Cabernet Sauvignon might well be expected to be described as powerful and heavy, Chilean Chardonnays are rarely described using such terms). What is more, there was no effect of the musical selection on how much the students liked the wine, thus suggesting that the music influenced the descriptive, rather than the evaluative, aspects of tasting.

North [34] explained his results in terms of the emotional attributes (or connotation; [37]) of music somehow priming the shared attribute in the wine itself (see also [22]). That is, North suggested that there may

Table 3 Main effect of type of music on ratings of wine (averaged over red and white wine) from North's study [34]

\begin{tabular}{llllll}
\hline \multirow{5}{*}{ Rating } & \multicolumn{3}{l}{ Music } & & \\
\cline { 2 - 6 } & $\begin{array}{l}\text { No } \\
\text { music }\end{array}$ & $\begin{array}{l}\text { Zingy/ } \\
\text { fresh }\end{array}$ & $\begin{array}{l}\text { Powerful/ } \\
\text { heavy }\end{array}$ & $\begin{array}{l}\text { Mellow/ } \\
\text { soft }\end{array}$ & $\begin{array}{l}\text { Subtle/ } \\
\text { refined }\end{array}$ \\
\hline Zingy/fresh & $4.91^{*}$ & 6.91 & 5.25 & 5.51 & 5.47 \\
Powerful/heavy & 4.38 & 4.71 & 6.78 & 4.35 & 5.88 \\
Mellow/soft & 5.53 & 5.51 & 6.31 & 7.12 & 6.68 \\
Subtle/refined & 4.96 & 4.86 & 5.61 & 4.78 & 6.47 \\
\hline
\end{tabular}

Table reprinted with permission

*A rating of 0 represented, "The wine definitely does not have this characteristic", and a rating of 10 represented, "The wine definitely does have this characteristic" 
Table 4 Musical selections suggested to match different grapes (recommendations taken from [35])

\begin{tabular}{l}
\hline Music recommendations to enhance the flavor of particular varietal wines \\
\hline Cabernet Sauvignon \\
"All along the Wachtower"-Jimi Hendrix \\
"Honky Tonk Woman"-The Rolling Stones \\
"Live and Let Die"-Paul McCartney and Wings \\
"Won't Get Fooled Again"-The Who \\
Chardonnay \\
"Atomic"-Blondie \\
"Rock DJ"-Robbie Williams \\
"What's Love Got to Do With It"-Tina Turner \\
"Spinning Around"-Kylie Minogue \\
Syrah \\
"Nessun Dorma"-Puccini \\
"Orinoco Flow"-Enya \\
"Chariots of Fire"-Vangelis \\
"Canon"-Johann Pachelbel \\
Merlot \\
"(Sitting on) The Dock of the Bay"-Otis Redding \\
"Easy"-Commodores \\
"Over the Rainbow"-Eva Cassidy \\
"Heartbeats"-Jose Gonzalez
\end{tabular}

Table reprinted, with permission, from [33]

have been some kind of linguistic or conceptual matching, or priming, going on here, whereby the music and wine share a common descriptor. Note that North specifically selected the musical pieces that he played to the participants on the basis that they had attributes that could be applied to both music and wine. In this sense, the starting point was clearly metaphor; that is, it was based on the fact that people use, or at least find it natural to use, the words such as "heavy" or "mellow" to refer to both music and wine. As North puts it, his results mostly show that "participants appeared to perceive the taste of the wine in a manner consistent with the connotations of the music" ([34], p. 298). Notice also here how the words chosen were not straightforwardly capturing a musical (i.e., auditory) characteristic of the piece but were themselves examples of what has been called metaphorical transfer [38] from the tactile modality (concerning temperature, texture, and weight). One worry here, then, is that North might have confirmed the attraction of certain metaphorical mappings between music, wines, and tactile attributes, more than necessarily having demonstrated a genuine perceptual effect (see [36]).

Given people's ability to extract a variety of meanings, or high-level concepts from music [39-41] $]^{4}$, moving forward, one could certainly imagine a host of other connotative transfer experiments of this type being undertaken in the future (cf. [42], for a conceptually similar approach to the study of the effect of music on the perception of the environment). So, for example, given that both music and wine can be described in terms of femininity/masculinity [40], might playing a strident masculine marching tune bring out that quality in a wine? Given what we have seen so far, there would appear to be no good reason why not (cf. [43])! One other point to bear in mind when considering the generalizability of North's results is his use of WEIRDo's. This acronym stands for Western, Educated, Industrialized, Rich, and Democratic students who typically take part in psychological research and who may not be all that representative of the population at large [44]. So, for example, one might imagine those young students to be somewhat less confident in their sensory abilities than more mature individuals. Relevant here, then, is Deliza and MacFie's [45] suggestion that such individuals might be influenced more by task-irrelevant peripheral information (such as background music) than more experienced/confident tasters.

Spence et al. [46] conducted an experiment in which regular consumers $(N=26)$ rated three wines as tasting significantly better when listening to matching music than when tasting the same wines in silence (see Fig. 1). Such results are consistent with Clark Smith's suggestions [32], outlined earlier. Spence and his colleagues first conducted a preliminary matching study in which a group of 26 participants had to rate how well each of four wines matched each of eight pieces of classical music. On the basis of the results, these researchers chose one particularly well-matched piece of music for each of the three wines. There are a few things to note about these results, however. On the one hand, the increase in liking for the wines that was observed while people listened to the matching music was certainly not huge (c. a $5 \%$ increase). Furthermore, while we know that the music was rated as a particularly good match for the wines that the participants were tasting (based on the results of [46], Experiment 1), what we cannot be so sure about (at least not in the absence of data from the appropriate experimental control condition) is whether it was simply the presence of music itself, or explicitly matching (or crossmodally corresponding) music, that was doing the work here. ${ }^{5}$ This will clearly be an important issue to resolve in future research. The same comment also applies when it comes to the fact that participants rated the wines as significantly sweeter (though note that all three wines are technically dry) when tasting in the presence of the matching music (as compared to silence). 


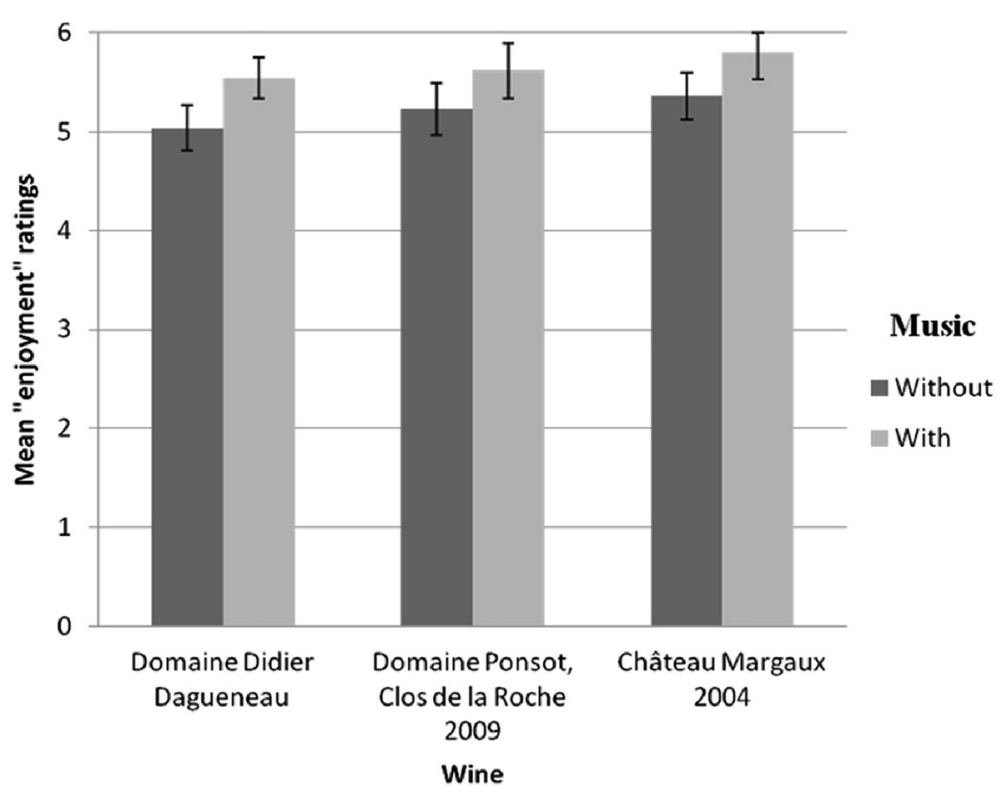

Fig. 1 Results of a study by Spence et al. [46] showing enhanced enjoyment ratings when people tasted wine while listening to matching music as compared to when tasting in silence. The pieces of music that were chosen to match the three wines here were Mozart's Flute Quartet No 1 in D major, K 285-Movement 1, Allegro; Ravel's String Quartet in F major-Movement 1, Allegro moderato-très doux; and Tchaikovsky's String Quartet No 1 in D major-Movement 2, Andante cantabile, respectively. (Figure reprinted from Spence et al. [46] with permission.)

Meanwhile, at a wine tasting event held at the 2014 Sensibus Festival in Seinäjoki, Finland, the audience members had to rate four wines twice, once while listening to the Rantatie quartet (see http://www.brq.fi/ en/) playing Mozart's Flute Quartet in D major, K285-Movement (played, in this case, by string quartet). Thereafter, they rated the wines a second time, while listening to Viljami Niittykoski's, Suvitunnelma (Summermood) instead. ${ }^{6}$ The four (distinctive) wines consisted of a Taittinger Brut Réserve champagne, a Fernway Sauvignon Blanc 2012 (white), a Chateau Carsin Cuvée Noire 2010 (red), and a Chateau Carsin Liquoreux 2007 (dessert wine). In this case, the participants ranked the wine tasted while listening to Mozart as more pleasant (regardless of how well the music matched the specific wine; [47]). However, a significant correlation was obtained between matching and liking, with those giving the wine a higher rating on one scale (matching or liking) likely to give it a higher rating on the other scale as well.

Wang and Spence [48] conducted a study in which roughly half of the audience at a cheese and wine event held in Oxford listened to putatively matching music (white wine with Debussy and red wine with Rachmaninoff) while the rest listened to music that was not expected to be so congruent (red wine with Debussy and white with Rachmaninoff). The wines consisted of a Marcel Martin Sauvignon Blanc 2013, from the Loire Valley in France, and a Para Dos Malbec 2013, from Mendoza, Argentina. ${ }^{7}$ The music was performed live by a duo of musicians from the Royal Academy of Music, London. The first piece of music was Debussy's Jardin Sous la Pluie, a virtuosic piano solo with many fast passages in a high pitch range. The second piece was Rachmaninoff's Vocalise, a piano and cello duet played in a slow tempo. ${ }^{8}$ The participants rated how well the music matched the wine (on a 100 point scale). They also had to try and assess the fruitiness, acidity, tannins, richness, complexity, length, and pleasantness of the two wines [49].

Once again, the music playing in the background exerted a significant influence over people's wine ratings (at least amongst the 64 members of the audience who returned completed score sheets). In particular, the wines were rated as tasting significantly fruitier while listening to Rachmaninoff than to Debussy ( $M=59.1$ vs. 51.5 , respectively), regardless of the type of wine (white or red). There was also a significant main effect of music on acidity, with the wines being rated as tasting significantly more acidic ${ }^{9}$ (by around $20 \%$ ) while listening to Debussy than to Rachmaninoff ( $M=65.3$ vs. 45.9 , respectively). Intriguingly, just as in North's [34] study reported earlier, the music appeared to have a similar effect on both wines. A final result to emerge from this study was that the participants once again rated the wine as more pleasant when the wine-music match was judged to be more congruent (cf. [50]). This and the similar result reported above by Spence et al. [47] can perhaps best be explained in terms of the notion of 
processing fluency [51-53]. That is, when the music and wine are congruent, the participants may be able to evaluate the sensory properties of both more easily (that is, the processing fluency is higher), and hence, they may find the experience a little more pleasant as a result. (By the same token, drinking wine while listening to incongruent, or mismatching, music should lead to reduced pleasantness ratings, as the combination will likely be more difficult to process.)

Wang and Spence [48] were especially interested in the question of whether the pace of the music playing in the background would exert an influence over the persistence of their participants' in-mouth flavor sensations. The suggestion here was that slower music might help to prolong the length of the wine (which most experts would consider a desirable change). To this end, Wang and Spence chose two pieces of music that had very different tempi: Debussy's Jardin Sous la Pluie, at roughly 150 beats per minute, and Rachmaninoff's Vocalise, at roughly 80 beats per minute. While no effect of length was reported in their main experiment (see above), it is worth noting that length may not be an attribute that social drinkers are necessarily all that good at tracking. Consequently, a follow-up study ( $N=23$ participants; including a few participants from the Oxford University blind wine tasting society) was conducted in which the order of presentation of the two musical selections was counterbalanced across participants (possible given the use of prerecorded music on this occasion). The meaning and assessment of length in wine was also clearly explained to the participants at the start of the study. Under such conditions, the wine that was tasted while listening to Rachmaninoff was rated as delivering a significantly longer in-mouth flavor sensation $(M=6.4 \mathrm{~s})$ than when listening to Debussy $(M=5.0 \mathrm{~s} \text {; see [48] })^{10}$

Intriguingly, a similar phenomenon (specifically, the lengthening of the wine) was anecdotally commented on by a number of those who attended the 2015 Campo Viejo Streets of Spain event in London. At this popular street festival, soundscapes that had been designed to match a selection of Campo Viejo wines were played to people while they tasted the matching wine. According to Nick Ryan, the synaesthetic Bafta-award-winning musician and composer behind the soundscapes, "A lot of people said that they didn't realise that the taste of wine lasted so long in the mouth until they were listening to the composition" ([54], p. 7). Unfortunately, however, it is unclear just how representative (or statistically significant) such comments were. ${ }^{11}$ Furthermore, it is impossible to know whether the appropriateness of the wine-sound match played any role here or whether a given soundscape might have lengthened the drinker's experience of whatever they were tasting. Nevertheless, taken together, the results that have been reported here would appear to provide at least prima facia evidence to suggest that music (and soundscapes) can be used to lengthen the in-mouth sensation associated with a wine.

One other salient attribute of many a wine is its astringency, which in noticeable quantities is rarely a desirable characteristic in wine (at least for the average North American palate). The North American winemaker Clark Smith [32], whom we came across earlier, certainly believes that the astringency of a wine can be modulated by music as well. At this point it may be best to hand over to the man himself:

Here's a fun experiment you can do at home: Open a nice big Cabernet Sauvignon, taste it and take note of the level of astringency. Boot up iTunes, put on the Doors' "People Are Strange" and taste again. You'll see the wine smooth out. Then put on "When The Saints Go Marchin' In" (Louis Armstrong's Golden Legends version will work). The wine will become almost undrinkably harsh. If you have a glass of White Zinfandel around, the effects will be the opposite....

Whether or not that makes sense, this experiment dramatically demonstrates the importance of context for astringency perception. In addition, it shows how strongly shared is our sense of harmony, however divided we are as to individual preference.

\section{Interim summary}

Taken together, the results of the various studies reported in this section clearly demonstrate that music can influence the wine drinking experience (see Table 5 for a review). In particular, people have been shown to rate wine as tasting significantly better while listening to matching music as compared to drinking in silence [46]. People (social drinkers) also appear to prefer wine while listening to Mozart's Flute Quartet in D major, K285Movement rather than to Viljami Niittykoski's, Suvitunnelma (Summermood; [47]). ${ }^{12}$ Furthermore, the better the match between the music and the wine (rated subjectively), the more pleasant the tasting experience (or vice versa; $[47,48])$. The latter result can perhaps best be accounted for in terms of the notion of processing fluency [51-53].

Beyond these general hedonic effects, however, more specific effects of certain music on the sensory aspects of the wine tasting experience - think acidity, sweetness, fruitiness, astringency, and length - have also been reported ([32, 46, 48, 54]). Additionally, researchers have also been able to demonstrate that the emotional connotations (or associations) of a piece of music can carry over to affect people's rating of the related descriptive attributes of a wine (see $[34,36])$. However, what remains a little more elusive at this stage is the extent to which 
Table 5 Summary of findings from scientific studies of the impact of different pieces of music on the wine tasting experience

\begin{tabular}{|c|c|c|c|}
\hline Study & Music & Effect on wine & Matching wine \\
\hline \multirow[t]{4}{*}{ North, 2012 [34] } & Carmina Burana-Orff & Powerful and heavy & \\
\hline & Waltz of the Flowers (from The Nutcracker) & Subtle and refined & \\
\hline & Just Can't Get Enough_Nouvelle Vague & Zingy and refreshing & \\
\hline & Slow Breakdown-Michael Brook & Mellow and soft & \\
\hline \multirow[t]{3}{*}{ Spence et al., 2013 [8] } & $\begin{array}{l}\text { Mozart's Flute Quartet No. } 1 \text { in D major, K 285- } \\
\text { Movement } 1\end{array}$ & $\begin{array}{l}\text { More enjoyable with music than } \\
\text { silence }\end{array}$ & $\begin{array}{l}\text { Domaine Didier Dagnueneau, Pouilly } \\
\text { Fumé Silex } 2010\end{array}$ \\
\hline & Ravel's String Quartet in F major-Movement 1 & & Domaine Ponsot, Clos de la Roche 2009 \\
\hline & $\begin{array}{l}\text { Tchaikovsky's String Quartet No } 1 \text { in D major- } \\
\text { Movement } 2\end{array}$ & $\begin{array}{l}\text { More enjoyable with music than } \\
\text { silence }\end{array}$ & Château Margaux 2004 \\
\hline \multirow[t]{2}{*}{ Spence, 2014 [68] } & $\begin{array}{l}\text { Mozart's Flute Quartet No. } 1 \text { in D major, K } 285 \text { - } \\
\text { Movement } 1\end{array}$ & $\begin{array}{l}\text { More enjoyable than } \\
\text { Suvitunnelma }\end{array}$ & Tattinger Brut Réserve \\
\hline & Viljami Nittykoki's Suvitunnelma & & Chateau Carsin Cuvée Noire 2010 \\
\hline \multirow{2}{*}{$\begin{array}{l}\text { Wang and Spence, in } \\
\text { press } b\end{array}$} & Debussy's Jardins Sous la Pluie & Higher acidity than Vocalise & Marcel Martin Sauvignon Blanc 2013 \\
\hline & Rachmaninoff's Vocalise & $\begin{array}{l}\text { Higher fruitiness than Jardins } \\
\text { Sous la Pluie }\end{array}$ & Para Dos Malbec 2013 \\
\hline
\end{tabular}

Table reprinted, with permission, from Wang and Spence [48]

the crossmodal congruency (or correspondence) between the wine and the music really matters to how the former influences the latter. So far, it would seem like the congruency between wine and music (operating at a general level) only affects people's liking for wine, whereas the congruency between individual wine attributes and music affects sensory ratings of wine regardless of overall congruency between the wine and the music. Further research is undoubtedly still needed in order to resolve this matter. Given the above, we would like to argue though that there is clearly more than enough published evidence out there to assertively counter the widespread skepticism about the effect of music on the flavor of wine, as expressed by people like Alice Jones, in the quote we came across earlier [1].

Thus far, all of the musical selections that have been utilized in the research have been picked off the shelf. However, it is worth noting that traditional music is not necessarily ideal when it comes to conducting research in this area. On the one hand, traditional music is rarely composed to convey or be associated with a specific taste, aroma, or flavor. ${ }^{13}$ On the other hand, music often changes over time, that is, it evolves from the start to end of a piece. Particularly striking examples of the stylistic changes that can occur in a piece of music can be found in Queen's Bohemian Rhapsody, say, or for those of a more classical bent, in Mozart's Piano Sonata No. 12 in $\mathrm{F}$ Major (K332), the latter varying between major and minor mode (both examples highlighted by [22]). As such, unless one is careful, there is a very real danger of picking a piece of music in which the different sections of the piece correspond to, or match up with, different tastes/flavors. Ideally, at least according to sound artist and composer Ben Houge, what one wants is something more akin to video game music that is forever evolving and yet always stays the same [55]. Given such potential constraints, it should come as little surprise to find that some researchers have recently started to compose their own music (and soundscapes) in order to convey a specific taste (e.g., [11, 56]; see also [57], for an evaluation of several different compositions designed to evoke the basic tastes), aroma ([58, 59]), or flavor ([54]).

Of course, it is important to note that any change in the perceived qualities of a wine resulting from the music playing in the background need not necessarily be liked. Just take the example of a quality Riesling: Such wines are often characterized by a fine balance between sweetness and sourness. If the impact of music on taste is as marked as some of the research outlined above would appear to suggest, then there could presumably be a danger that accidentally playing "sweet music" would adversely affect the balance of the wine (that the highly skilled winemaker has worked so hard to achieve), and thus, spoil the experience for the drinker (see also [22] on this theme). And anyone who has been at one of the wine-music events hosted by Barry Smith and Charles Spence over the last couple of years (e.g., $[60,61]$ ) will know only too well how an even modestly fresh/acidic white wine can become almost undrinkable when the sour notes in the wine are accentuated by playing some of Bruno Mesz's mathematically transformed Argentinian tango (see [56]) or else Nils Oklan's, Horisont. We have also recently published research showing how dissonant (as compared to consonant) music tends to accentuate sourness [62]. On the other hand, 
however, one could also imagine "sweet" music to mute the tannic astringency in a young oaked Rioja, say (see [5], for evidence on this score; and see Clark Smith's [32] observations above). One could think of this in terms of "sonic seasoning" [63]. Thus, the key point to bear in mind here is that what we hear changes what we taste, whether that is a good or bad thing (i.e., leads to a better or worse tasting experience), depends both on the particular qualities of the wine that we happen to be tasting and our own particular wine predispositions. ${ }^{14}$

Thus, the skeptic, or wine expert might still be tempted to say "Just give me a good, well-balanced wine, and let's just forget about the music." While it is perhaps not possible to enhance a great wine through music, what such a viewpoint fundamentally fails to recognize is that the experience of drinking a truly great wine can be impaired if the wrong music happens to be playing. ${ }^{15}$ Indeed, as a general rule, it would seem fair to suggest that the better the wine, the harder it will be for music to enhance the experience. Unfortunately, on the other hand, it would seem likely that playing the wrong music (think Mozart's Flute Quartet in D major, K285 while drinking a 2004 Château Margaux or Tchaikovsky's String Quartet No 1 in D major when tasting Domaine Didier Dagueneau, Pouilly Fumé Silex 2010, as documented by the participants who took part in Spence et al.'s [46] study) can easily detract from the wine drinking experience, no matter how expensive the bottle (though note here that the wines in Spence et al.'s [46] study retailed at well in excess of $£ 100$ a bottle). Meanwhile, Pete Brown ([64], p. 28) has suggested that it is more or less impossible to imagine any wine going with country music or punk. ${ }^{16}$

Here, it is also worth bearing in mind that there are those who prefer to drink (or should that be taste) their wine in silence. As the famous French oenologist Emile Peynaud once said, "The sense of hearing can interfere with the other senses during tasting and quiet has always been considered necessary for a taster's concentration. Without insisting on absolute silence, difficult to obtain within a group in any case, one should avoid too high a level of background noise as well as occasional noises which can divert the taster's attention. During exercises demanding very precise tasting, participants should not be allowed to talk to each other. Indeed anything which might distract the taster or make him uncomfortable is undesirable." ([65], p. 104). Indeed, for those who are trying to taste analytically, one could imagine that silence would be preferable (in fact, avoiding anything that would distract the taster's attention from the task at hand). However, as we will see below, regular drinkers, by contrast, would generally seem to prefer a little music with their wine, especially if it is not too loud (see [27]). They, after all, are looking to have the best multisensory experience they can.

\section{So, how, exactly does music influence the sensory attributes of the wine?}

Having demonstrated the robust effects that (matching) music can have on the taste/flavor of wine, the next question has to be "How?" There are a number of ways in which any correspondence (or match) between the music we are listening to, and the wine we are tasting, could occur: Suggested mechanisms include synaesthesia (which we have dismissed already, so will not spend any more time on here; see [3]), the focusing of a person's attention via the crossmodal correspondences that are present between music and wine, an emotional mediation account, and possibly also neural cross-wiring. Two other accounts that have been briefly covered already are "sensation transference" [66] and crossmodal masking [24].

\section{Attention and crossmodal correspondences}

It is possible that the sounds and music we hear may draw our attention to a specific element on a wine. One way in which this could happen is via attention (though note that attention is not strictly necessary here). It is well known (at least to psychologists) that attention can enhance the salience of the attended stimulus, or feature, relative to when the same stimulus, or feature, is unattended (see [67, 68]; though see also [69, 70]). What is also known is that the effects of attention on awareness tend to become more pronounced as the perceptual input becomes more challenging/complex [71, 72]; and wines, at least quality wines, can certainly be considered as complex flavor stimuli [73]. Indeed, laboratory research suggests that people are unable to extract more than two or three aromas from complex odor mixtures, even if they had been exposed to the individual components beforehand $[69,74-76] .^{17}$

Such crossmodal attentional effects may be at the root of at least some of the effects of music on taste perception. To be absolutely clear here, the suggestion is that by paying attention to the music we are listening to, our attention might be drawn toward one component of the rich sensory experience associated with a wine rather than another (i.e., in much the same way that a wine label, or for that matter, the eloquent words of the wine expert leading a tasting, can draw our attention to something in the wine that was not so clear otherwise). "What seemed to be happening was not that we noticed new flavors when the music changed. Instead, the same flavor elements were there all along, but the music seemed to change the way we perceived them. Some 
music made us pay more attention to astringency, so we disliked the wine. With other music, we chose to ignore the oak and tannin, so we liked it more" ([77]). Such crossmodal effects could occur in either a stimulusdriven (exogenous) or voluntary (endogenous) manner.

Relevant here, in conceptually analogous research, it has previously been shown that playing a task-irrelevant high-pitched sound can exogenously draw a person's attention upward, hence resulting in their responding more rapidly to visual stimuli presented in the upper part of a visual display than equivalent stimuli presented lower down in the display (see [78]). In research conducted here in Oxford, we have found that the presentation of high- versus low-pitched sounds can facilitate people's ability to pick out a specific visual target from in-amongst a cluttered array of flickering visual distractors [79]. Both of these perceptual enhancement effects appeared to occur in a fairly bottom-up or stimulusdriven manner.

One could, however, also foresee how such crossmodal attentional effects might operate here in more of a voluntary, or top-down, manner as well. So, for example, anyone who was aware of Hector Berlioz's [80] early suggestion that the sound of the oboe has an "acid-sweet voice" might voluntarily choose to direct their attention to the balance between acidity and sweetness of a wine say, in a way, that someone who was unfamiliar with the composer's suggestion might not when listening to the instrument. One could similarly imagine how someone who was musically trained would think of the term "dolce" (Italian), used since the 19th century to describe music played in a soft and non-staccato manner. Such individuals might then voluntarily choose to focus their attention on a different aspect of their taste/flavor experience than someone else who was unfamiliar with this musical term. In fact, one of the open questions in this area of research (both in the audiovisual arena, just described, but also in the wine-music case) is the extent to which people need to explicitly attend to the music (or sound) and the possible connection between what they are hearing and their tasting experience, for these kinds of crossmodal effects to occur.

Certainly, what we know for sure is that the attention of the participants and audience members in the various experiments and demonstrations that have been reported thus far in this piece have undoubtedly been actively encouraged to look for any connections that might exist between the different sensory experiences they were having. Would similar effects occur when music is playing incidentally in the background in a wine bar, say? That is one of the key questions to which we do not yet have a clear answer. In most, if not all, of the studies that have been reviewed here, the fact that the music was relevant to the wine tasting experience was made apparent to the participants/tasters. It must remain an open question, therefore, as to whether for any music that just so happens to be playing incidentally, similar crossmodal effects would be observed or whether instead these kinds of effects require the taster to actively link their tasting experience with what they are hearing ([81]; see also [82, 83], on the automaticity of crossmodal correspondences).

Finally, here, one should probably also leave open the possibility that any crossmodal effects of music on wine perception may have, at least in part, a direct, low-level, neurophysiological basis (i.e., one that does not require the involvement of attention). Such a suggestion is inspired by Wesson and Wilson's [84] surprising discovery a few years ago of direct connections between the ear and the olfactory tubercule (at least in the animal model; see also [85]). Now, should similar cross-sensory connections also be present in us humans, one can only speculate as to what their consequence for wine tasting while listening to music might be. ${ }^{18}$

\section{Emotional mediation of music's influence on taste}

One other important way in which what we hear likely influences what we taste is via the ability of music to affect our emotions. As was mentioned earlier, listening to music can put us in a certain mood or emotional state (see [21, 86], cf. [87]), either positive or negative. This too might be expected to influence our perception and appreciation of wine (e.g., $[22,23])$. It is certainly easy to imagine how any change in the mood/emotional state of the wine drinker could affect how much they enjoy the experience (see [88, 89]). Gray ([31], p. 2) seems to be getting at something of this sort when he said, "Red wines need either minor key or they need music that has negative emotion. They don't like happy music...Cabernets like angry music."

However, the key question here is whether mood or emotion also affects the sensory-discriminative aspects of tasting. The evidence here suggests that indeed it can. So, for example, it has been shown that a person's mood can influence their ability to detect both olfactory (e.g., [90]) and gustatory stimuli ([91-93]). In one representative study, Pollatos et al. [90] presented their participants with pleasant, unpleasant, and neutral pictures from the International Affective Picture System (IAPS) database. After having viewed a selection of the unpleasant pictures, the participants' sensitivity to olfactory stimuli was lowered, as a result of the negative emotional stimulation. Elsewhere, it has been shown that those individuals who are anxious tend to be less sensitive to bitter and salty tastes [91, 92]. Normal individuals who are stressed become somewhat more sensitive to the bitter taste of saccharin [94]. Emotion has also been shown to affect olfactory perception [95]. 
Is it possible to discriminate between the effects of crossmodal correspondence and attention on the one hand, and the effect on tasting of a music-induced change in the taster's mood or emotional state, on the other? It is here that an assessment of the time-course of music's effect on the wine tasting experience potentially becomes informative. It could well be imagined that any emotional impact of music on the mood of the person listening to it would take some time to build up (around $8 \mathrm{~s}$, at least according to Bachorik et al., [96]). Hence, one might imagine that if the effect of music on taste were attributable to the changing emotional state of the listener, then this would also take time to emerge. By contrast, any effect of music on taste that results from the music-taste crossmodal correspondences serving to direct the listener's attention to a different element of their tasting experience might potentially occur fairly instantaneously, especially if a simple sound is played; Just imagine a sustained musical chord. So, with this groundwork in hand, the question is what does the literature have to say on this matter?

To date, there have not been many studies that have explicitly addressed this question. However, a number of anecdotal reports have stressed the seemingly immediate effect on the taster's perceptual experience of changing the music or changing some element of the music. So, for example, in our largescale tasting event held at the 2014 Streets of Spain festival in London [5], people were invited to enter a windowless white rectangular space. Once inside, with a glass of rioja in their hands (in a black tasting glass so that they could not see its visual appearance), they were asked to rate the wine. After a couple of minutes, the lighting was changed to either red or green; the drinkers rated the wine again. Then the lighting was changed twice more, and each time music was played. Specifically, we chose to play putatively "sweet" music with the red lighting and "sour" music with the green lighting [11]. The change in the music synchronized with the change in the lighting. Each time there was a change in the lighting and/or music, the drinkers rated the wine afresh. Now what was striking about this event were comments, such as the following that the taste of the wine changed immediately that the lighting/music changed. As one attendee put it, "Fascinating! Flavour/colour connection: The change was instant. How curious!" Such anecdotal reports suggest that the effect of music (and/or lighting-unfortunately we cannot be sure quite which it was) was having a direct influence on the tasting experience, perhaps more consistent with an account in terms of crossmodal correspondences directing a taster's attention than in terms of an emotional mediation account.
The second piece of anecdotal evidence comes from a series of tasting events that were held in Santa Rosa, California, in December, 2010, and in Paris, in April, 2011 (and described by Alexis Crawshaw [22]). The event was hosted by Clark Smith, and the small audience (12 in California and 5 in Paris) were made up of musicians and wine experts. The audience got to taste chardonnays, cabernets, and a merlot. Not much information is provided about the music other that the selections "were largely tonal works from the savant tradition, jazz and other contemporary popular styles." Now, given what we have seen so far, it should come as no surprise that "The change and fluctuations of musical parameters (such as tempo, musical mode, timbre) specifically altered the perception of a wine's taste (particularly sweetness and bitterness) and smell (i.e., which scent of the wine's bouquet emerged the most)" (see also [97] on soundscapes that can enhance bitterness and/or sweetness). But what is more interesting here is the next observation, "The gustatory and olfactory changes perceptually appear to occur immediately, coinciding with changes in mode (e.g., major to minor), tempo, and more generally, the style/genre. These changes can occur from work to work or within the same piece. For example, we noticed fluctuations when listening to such dynamic works as Mozart's Piano Sonata No. 12 in F Major (K332), which varies rapidly between styles of the day and also between major and minor, and Queen's 'Bohemian Rhapsody', with its distinct stylistic sections" ([22]).

Thus, while such results are consistent with an account of music's influence on the sensory aspects of the tasting experience in terms of crossmodal correspondences directing the taster's attention, we cannot rule out the possibility that emotional/mood-induced effects might not also take effect later on.

\section{Conclusions}

In this article, we have argued that there are likely a number of routes by which what we hear, focusing here specifically on music, can influence the sensorydiscriminative attributes of wine tasting. The focus here has been on the modification of specific sensory attributes, such as sweetness, acidity, fruitiness, astringency, and length. Such effects can be distinguished from the more generic hedonic effects of music that were outlined at the start (and which have already been studied extensively). We believe that the crossmodal correspondences that have been documented between music, and musical parameters, and tastes, aromas, mouthfeel characteristics, and flavors provide the best explanation and that the focusing of attention on certain elements in the complex flavor experience that is offered by a quality 
wine and which is elicited by the music as explaining many of the perceptual effects that have been demonstrated.

Beyond that, it would seem likely that the emotional response that can be induced by listening to music could also be having some impact on the tasting experience [22]. Finally, here, while summarizing the influence of music on specific sensory properties, it is worth bearing in mind that should the music get too loud, the perception of sweetness may be suppressed while the perception of umami is enhanced (see [24]; see also [98]).

Looking forward, one of the questions that we still do not have an answer to is whether there are any salient individual differences in the impact of music on the perception of wine. Would wine experts, be they wine writers, or better still, the wine tasters and wine makers, be equally affected? And what about trained musicians? One might expect wine makers to be better able to focus their attention solely on the sensory properties of the wine. In fact, the whole area of individual/cultural differences in wine-music matching is one that awaits thorough investigation (see [99], for related work in this area). What limited research has been conducted so far, though, suggests that music that has been composed in one country to convey a specific taste is also associated with the same taste by those coming from a different musical/ cultural background (see [11]).

As the research reviewed here has hopefully made clear, over and above the various general effects on the sensory-discriminative and hedonic aspects of tasting that can be induced by music. A rapidly growing body of empirical research now demonstrates that matching wines can bring something out in the wine, and hence, change people's experience when tasting wine. Finally, it is perhaps also worth bearing in mind the impact that the music can have both on what we choose to drink and how rapidly and how much we end up drinking (see $[20,29]$ for reviews).

While the focus in this piece has been squarely on wine, there is absolutely no reason why what has been done so far in the sphere of wine-music matching could not also be done for a variety of other beverages, both alcoholic and non-alcoholic. Indeed, as it happens, the very first studies to be published in the area of sound influencing taste were actually conducted with Carlsberg beer by Kristan Holt-Hansen $([100,101])$ in Copenhagen. In his seminal early work, Holt-Hansen demonstrated that people would match Carlsberg Elephant lager to a higher pitch than regular Carlsberg lager (perhaps because of its higher alcohol content; see also [55]). More importantly (for the focus of this article), when participants tasted a beer while a matching sound (a tone at the pitch of harmony) was played, they reported a variety of sensational experience such as "outspoken delight, bodily harmony, and relaxation." Though getting to the bottom of that story will be the subject for another day (see [63]).

\section{Endnotes}

${ }^{1}$ Who knows whether this might not also be the same motivation underlying Laithwaite's wine sponsoring a show on the Classic FM radio station a couple of years ago (http://radiotoday.co.uk/2013/09/ llewelyn-bowen-to-sell-wine-on-classic-fm/ on $08 / 08 /$ 2014; see also [102]).

${ }^{2}$ When thinking about music's influence on the perception of wine, it can be helpful to discriminate between four potentially different kinds of judgments that we may be tempted to ascribe to, or impressions that we may form about, a wine: Hedonic-how much do we like the wine?; Sensory-our assessment of the physical properties of the drink (sweetness, acidity, fruitiness, alcohol) and their impact on the drinker (grippiness, length, etc.); Analytic-concerning such attributes of age, complexity, balance, quality, and price assessment; and Descriptive-would we describe the wine as heavy or light, zingy or lush, masculine, or feminine?

${ }^{3}$ As a professional wine critic and wine judge, Jo Burzynska has also been experimenting with affecting her audience's wine tasting experience by playing different music. Based over in New Zealand, she has found that Marlborough Sauvignon Blanc is the wine style that can be changed most radically by sound (inspired by North's [34] work, she normally uses Nouvelle Vague's, Just Can't Get Enough as the positive track). For a track that has a negative impact on the wine, she recommends Skeptics-AFFCO http://itunes.apple.com/gb/album/skeptics/id213543574. In terms of wines, she recommends http://julestaylor.com/ our-wines/sauvignon-blanc/sauvignon-blanc-2011/, as a possible Sauvignon Blanc, and for an interesting contrast, a Marsanne or an Arneis.

${ }^{4}$ Watt and Quinn [40] found that music can be reliably associated with many higher level precepts, such as male/female and old/young.

${ }^{5}$ We performed a pilot study with 19 participants where two wines were tasted while listening to organ and harp music (a previous study had shown that participants associated the specific white wine with harp and the specific red wine with organ). Participants rated each wine-music combination for liking and matching. Significant differences were observed in matching scores for the red wine, where organ $(M=4.2$ out of 7$)$ was rated as a significantly better match for the red wine than the harp $(M=2.7)$, even though, overall, the participants liked the harp music significantly more than the organ music $(M=5.4$ out of 7 for 
harp and 3.7 for organ). Bivariate Pearson correlations showed wine-music matching ratings were significantly correlated with wine liking $(r=0.238)$ but not music liking. So it would seem that the participants were able to isolate the wine-music matching task from music enjoyment but not wine enjoyment.

${ }^{6}$ Note that one of the problems associated with conducting research at public events is the difficulty of perfectly counterbalancing one's conditions. Ideally, here, half of the audience would have heard the two pieces of music in the opposite order. On this occasion, however, the constraints of the live music event meant that this was simply not possible.

${ }^{7}$ The tasting notes for the white wine talked of grass, citrus, and gooseberry notes, light body, and high acidity, while for the red, black fruit, oak, and vanilla notes, medium body, medium acidity, and soft tannins were mentioned.

${ }^{8}$ The first piece was chosen to match the white wine, since high tempo and pitch have been shown to be associated with a sour taste and citrus flavours. The second piece was chosen to match the red wine, since legato articulation and a consonant melody have both been shown in prior research to be matched with sweet tastes and full body $[58,103]$.

${ }^{9}$ The increased sour ratings for wine while listening to the Debussy piece might have been attributable to the Debussy piece containing more dissonant chords overall than the Rachmaninoff piece. Wang and Spence [62] recently demonstrated that dissonant music increases participants' sourness ratings of fruit juice on a sweet-sour scale.

${ }^{10}$ Once again, the wines were both rated as somewhat more fruity while listening to Rachmaninoff $(M=67.1)$ than while listening to Debussy $(M=56.6)$. Intriguingly, however, no effect of music on acidity was reported, perhaps suggesting that the significant change reported in Wang and Spence's [48] main study should be attributed to order effects, rather than necessarily to the effect of music on wine perception.

${ }^{11}$ Furthermore, when the second author attended the festival, they were explicitly told at the onset that the music for red wines had been specifically composed in order to lengthen the finish. In practice, after the signal was given for participants to swallow the wine, the music morphed into a single long sustained string note. One possibility was that participants may have mentally linked the residual taste with the note, so as long as the sound was unbroken, the taste also lingered.

${ }^{12}$ For those who were wondering about this Finnish piece, according to the description in Spence et al. [47]: "The melancholy, wistful melody of the song begins after the overture with unhurried, folk rhythm. The ambience grows gradually from wistful to an overwhelming sense of melancholy. The melody climbs an octave higher with intensifying accompaniment."

${ }^{13}$ With the possible exception of certain classical pieces such as J. S. Bach's (1732) Coffee Cantata. This secular piece of music, published in Leipzig, was written for soprano, tenor, and bass solos and orchestra. Carl G. Hering also composed a "Coffee canon" in the late $19^{\text {th }}$ Century. Were these composers, one might ask, trying to make music to match the taste of coffee? A quick look at the German lyrics suggests that this is not quite what Hering had in mind; they translate roughly as "C-a-f-f-e-e, don't drink so much coffee. Not for children is the Turkish drink..."

${ }^{14}$ Remember here that in a very real sense we do all live in different taste worlds [104].

${ }^{15}$ One might discard this concern by thinking it would be highly unlikely to encounter the wrong music while drinking a good or expensive wine. However, given the increasing level of noise in restaurants these days, having your nice wine ruined by a loud atmosphere (just think Cristal Champagne in nightclubs) is a very real concern [27].

${ }^{16}$ That said, in the second author's student days organizing the Cheap Wine Society at MIT, Rex Goliath Merlot (a cult under $\$ 5$ wine) was found to go wonderfully together with bluegrass music. According to the tasting notes, the "mouth-filling flavors of plums, cherries and wild red berries dominate from start to finish. Soft, supple and complex. Pretty and seductive with a decidedly spicy nose of black cherry, cassis and cedar" (see http:// www.rexgoliath.com/merlot.php\#.Vc4WXPIViko).

${ }^{17}$ Now, while the conclusion here might be striking, one important limitation with these series of studies relates to the use of unrelated olfactants, such as, for example, carvone (spearmint), benzaldehyde (almond), cis-3 hexanal (cut grass), limonene (orange), eugenol (cloves), and ethyl-n-butyrate (unspecified fruity) in the odor mixtures. It is perhaps unsurprising, given such a set-up, that the participants were simply not able to identify more than three components from within the mixture. If it were always true that people could only identify a maximum of three odorants, it would be very hard to justify those wine writers who can deliver more than 1000 words describing the sensory attributes of a wine in their tasting notes [105]. Here, it is important to consider how the chunking of structured olfactory information might enable the experienced taster to get more from a wine. Just think, for example, of an expert tasting what $\mathrm{s} / \mathrm{he}$ takes to be a red Burgundy (which they might have discerned from the color). They already know to look out for cherry, earth, and vegetal notes from the wine.

${ }^{18}$ Note, though, that this form of cross-wiring, should it exist, would still not be labeled as 
synaesthesia, as the perceptual consequences would likely be shared by us all (hence failing the idiosyncratic criterion).

\section{Competing interests}

The authors declare that they have no competing interests.

\section{Authors' contributions}

CS \& Q(J)W wrote all parts of this review. Both authors read and approved the final manuscript.

\section{Acknowledgements}

CS would like to acknowledge the AHRC Rethinking the Senses grant (AH/L007053/1)

Received: 20 August 2015 Accepted: 10 November 2015 Published online: 20 November 2015

\section{References}

1. Jones A. A far from vintage show as Callow uncorks the clichés. The Independent; 2012. [http://www.independent.co.uk/arts-entertainment/tv/ features/the-week-in-radio-a-far-from-vintage-show-as-callow-uncorks-theclich-s-8269761.html]. Accessed 3 August 2015

2. Sachse-Weinert M. Wine \& musik: $2+2=5$ [Wine \& music: $2+2=5$ ] Vortrag im Rahmen der Ringvorlesung "Weinwissenschaft" an der Johannes Gutenberg-Universität Mainz im Sommersemester. Presentation given on 4 July 2012

3. Spence $C$, Wang $\mathrm{Q}(\mathrm{J})$ : Wine \& music (I): On the crossmodal matching of wine \& music. Flavour (submitted).

4. Oberfeld D, Hecht $H$, Allendorf U, Wickelmaier F. Ambient lighting modifies the flavor of wine. J Sens Stud. 2009:24:797-832

5. Spence C, Velasco C, Knoeferle K. A large sample study on the influence of the multisensory environment on the wine drinking experience. Flavour. 2014;3:8

6. Sachse-Weinert M. Voce:divino in München. Synästhesie in perfektion. Voce: divino in Munich: Pure synaesthesia]. Weinfeder Journal. 2014;43:34-5.

7. Spence C. Crossmodal correspondences: a tutorial review. Atten Percept Psychophys. 2011;73:971-95.

8. Spence C. On crossmodal correspondences and the future of synaesthetic marketing: matching music and soundscapes to tastes, flavours, and fragrance. In: Bronner K, Hirt RC, Ringe $C$, editors. (((ABA))) Audio Branding Academy Yearbook 2012/2013. Baden-Baden: Nomos; 2013. p. 39-52.

9. Belkin K, Martin R, Kemp SE, Gilbert AN. Auditory pitch as a perceptua analogue to odor quality. Psychol Sci. 1997:8:340-2

10. Deroy O, Crisinel A-S, Spence C. Crossmodal correspondences between odors and contingent features: odors, musical notes, and geometrical shapes. Psychon Bull Rev. 2013:20:878-96.

11. Knöferle KM, Woods A, Käppler F, Spence C. That sounds sweet: using crossmodal correspondences to communicate gustatory attributes. Psycho Market. 2015:32:107-20

12. Knöferle KM, Spence C. Crossmodal correspondences between sounds and tastes. Psychon Bull Rev. 2012:19:992-1006.

13. Areni CS, Kim D. The influence of background music on shopping behavior: classical versus top-forty music in a wine store. Adv Consum Res. 1993;20: $336-40$

14. North AC, Shilcock A, Hargreaves DJ. The effect of musical style on restaurant customers' spending. Environ Behav. 2003;35:712-8

15. Yeoh JPS, North AC. The effects of musical fit on choice between two competing foods. Music Sci. 2010;14:127-38.

16. North AC, Hargreaves DJ, McKendrick J. In-store music affects product choice Nature. 1997:390:132.

17. North AC, Hargreaves DJ, McKendrick J. The influence of in-store music on wine selections. J Appl Psychol. 1999:84:271-6.

18. Schildknecht D. Authenticity in wine: playing by the rules. The World of Fine Wine. 2006:12:74-9.

19. White P. Food of love: wine and music. The World of Fine Wine. 2008;21:120-3.

20. Spence C, Piqueras-Fiszman B. The perfect meal: the multisensory science of food and dining. Oxford: Wiley-Blackwell; 2014.

21. Juslin PN, Sloboda JA. Handbook of music and emotion: theory, research, applications. Oxford: Oxford University Press; 2010.
22. Crawshaw A. How musical emotion may provide clues for understanding the observed impact of music on gustatory and olfactory perception in the context of wine-tasting. Unpublished manuscript. 2012

23. Smith BC: The emotional impact of a wine and the Provencal rose paradox. Unpublished manuscript, 2009.

24. Yan KS, Dando R. A crossmodal role for audition in taste perception. J Exp Psychol Hum Percept Perform. 2015;41:590-6.

25. Stafford LD, Fernandes M, Agobiani E. Effects of noise and distraction on alcohol perception. Food Qual Pref. 2012;24:218-24.

26. Stafford LD, Agobiani E, Fernandes M. Perception of alcohol strength impaired by low and high volume distraction. Food Qual Pref. 2013;28: 470-4.

27. Spence $C$. Noise and its impact on the perception of food and drink Flavour. 2013;3:9

28. Reinoso Carvalho F, Van Ee R, Rychtarikova M, Touhafi A, Steenhaut K, Persoone $D$, et al. Using sound-taste correspondences to enhance the subjective value of tasting experiences. Front Psychol. 2015:6:1309.

29. North A, Hargreaves D. The social and applied psychology of music. Oxford: Oxford University Press; 2008.

30. Spence C, Shankar MU. The influence of auditory cues on the perception of, and responses to, food and drink. J Sens Stud. 2010;25:406-30.

31. Gray WB. Music to drink wine by: Vintner insists music can change wine's flavors. San Francisco Chronicle; 2007. [http://www.sfgate.com/wine/article/ Music-to-drink-wine-by-Vintner-insists-music-can-3235602.php]. Accessed 7 August 2015.

32. Smith C. Astringency and harmony in tannins. Wines \& Vines; 2010. [http:// www.winesandvines.com/template.cfm?section=columns_ article\&content $=78078]$. Accessed 8 July 2015 .

33. Spence C. Wine and music. The World of Fine Wine. 2011;31:96-104.

34. North AC. The effect of background music on the taste of wine. $\mathrm{Br} J$ Psychol. 2012;103:293-301.

35. Anon. Music "can enhance wine taste". BBC News; 2008. [http://news.bbc.co. uk/go/pr/fr/-/1/hi/uk/7400109.stm]. Accessed 4 August 2008

36. Spence C, Deroy O. On why music changes what (we think) we taste. i-Perception. 2013;4:137-40.

37. Walker P. Cross-sensory correspondences and cross talk between dimensions of connotative meaning: visual angularity is hard, high-pitched and bright. Atten Percept Psychophys. 2012;74:1792-809.

38. Williams JM. Synthetic adjectives: a possible law of semantic change Language. 1976;52:461-78.

39. Rigg MG. An experiment to determine how accurately college students can interpret intended meanings of musical compositions. J Exp Psychol. 1937; 21:223-9.

40. Watt R, Quinn S. Some robust higher-level percepts for music. Perception. 2007:36:1834-48

41. Baraldi FB, De Poli G, Roda A. Communicating expressive intentions with a single piano note. J New Music Res. 2006:35:197-210.

42. Yamasaki T, Yamada K, Laukka P. Viewing the world through the prism of music: effects of music on perceptions of the environment. Psychol Music 2015:43:61-74

43. Krishna A, Elder RS, Caldara C. Feminine to smell but masculine to touch? Multisensory congruence and its effect on the aesthetic experience. J Consum Psychol. 2010:20:410-8.

44. Henrich J, Heine SJ, Norenzayan A. The weirdest people in the world? Behav Brain Sci. 2010;33:61-135.

45. Deliza R, MacFie HJH. The generation of sensory expectation by external cues and its effect on sensory perception and hedonic ratings: a review. J Sens Stud. 1996:2:103-28.

46. Spence C, Richards L, Kjellin E, Huhnt A-M, Daskal V, Scheybeler A, et al. Looking for crossmodal correspondences between classical music \& fine wine. Flavour. 2013;2:29.

47. Spence C, Velasco C, Vanne M, Hopia A. Can you taste the music? In: Hopia A, Ihanus S, editors. 5D cookbook. Seinäjoki: KUMURU-project; 2014. p. 73

48. Wang $Q(J)$, Spence $C$. Assessing the effect of musical congruency on wine tasting in a live performance setting. i-Perception. 2015;6:1-13.

49. Fielden C. Exploring the world of wines and spirits. London: Wine \& Spirit Education Trust; 2009

50. Seo H-S, Hummel T. Auditory-olfactory integration: congruent or pleasant sounds amplify odor pleasantness. Chem Senses. 2011:36: 301-9. 
51. Labroo AA, Dhar R, Schwartz N. Of frog wines and frowning watches: semantic priming, perceptual fluency, and brand evaluation. J Consum Res. 2008;34:819-31.

52. Lee AY, Labroo AA. The effect of conceptual and perceptual fluency on brand evaluation. J Marketing Res. 2004:41:151-65.

53. Winkielman P, Schwarz N, Fazendeiro T, Reber R. The hedonic marking of processing fluency: implications for evaluative judgment. In: Musch J, Klauer KC, editors. The psychology of evaluation: affective processes in cognition and emotion. Mahwah: Lawrence Erlbaum; 2003. p. 189-217.

54. Knapton S. Why sparkling wine sounds like beans falling on a plastic tray. The Daily Telegraph; 2015. [http://www.telegraph.co.uk/news/science/ science-news/11577381/What-does-wine-sound-like-Youre-about-to-findout.html]. Accessed 15 August 2015.

55. Anon. The search for metaphorical matchings through wine and music. 2015. http://www.1855oxford.com. Accessed 12 August 2015.

56. Mesz B, Sigman M, Trevisan MA. A composition algorithm based on crossmodal taste-music correspondences. Front Human Neurosci. 2012;6:1-6.

57. Wang $\mathrm{Q}(J)$, Woods A, Spence C. "What's your taste in music?" A comparison of the effectiveness of various soundscapes in evoking specific tastes. iPerception (in press).

58. Bronner K, Frieler K, Bruhn H, Hirt R, Piper D. In: Cambouropoulos E, Tsougras C, Mavromatis P, Pastiadis K, editors. What is the sound of citrus? Research on the correspondences between the perception of sound and flavour. Thessaloniki, Greece: Proceedings of the ICMPC - ESCOM 2012 Joint Conference; 2012. p. 42-8.

59. Crisinel A-S, Jacquier C, Deroy O, Spence C. Composing with cross-modal correspondences: music and smells in concert. Chemosens Percept. 2013;6:45-52.

60. McKenna G. Wine Vision: wine must engage all the senses, say professors. Harpers; 2014. [http://www.harpers.co.uk/news/wine-vision-wine-must-engageall-the-senses-say-professors/373655.article]. Accessed 10 August 2015.

61. Siddle R. Wines of Argentina's Cambalache event shows way ahead for consumer wine tastings. Harpers; 2013. [http://www.harpers.co.uk/wines-ofargentinas-cambalache-event-shows-way-ahead-for-consumer-winetastings/346742.article]. Accessed 10 August 2015.

62. Wang $Q(J)$, Spence C: "Striking a sour note": assessing the influence of consonant and dissonant music on taste perception. Multisens Res. 2015;29: 195-208.

63. Spence C, Wang Q(J): Wine \& music (III): so what if music influences taste? Flavour (submitted).

64. Brown P. Ale, ale, rock and roll! Word Magazine. 2012;3:28-9.

65. Peynaud E. The taste of wine: the art and science of wine appreciation (Trans. M. Schuster). London: Macdonald \& Co; 1987.

66. Cheskin L. How to predict what people will buy. New York: Liveright; 1957.

67. Driver J. A selective review of selective attention research from the past century. Br J Psychol. 2001;92:53-78.

68. Spence C. Orienting attention: a crossmodal perspective. In: Nobre AC, Kastner S, editors. The Oxford handbook of attention. Oxford: Oxford University Press; 2014. p. $446-71$.

69. Laing DG, Glenmarec A. Selective attention and the perceptual analysis of odor mixtures. Physiol Behav. 1992;52:1047-53.

70. Stevenson RJ. The role of attention in flavour perception. Flavour. 2012;1:2.

71. Lavie N. Perceptual load as a necessary condition for selective attention. J Exp Psychol Hum Percept Perform. 1995;21:451-68.

72. Lavie N. Distracted and confused?: Selective attention under load. Trends Cogn Sci. 2005;9:75-82.

73. Smith BC. Questions of taste: the philosophy of wine. Oxford: Oxford University Press; 2007.

74. Laing D, Francis $G$. The capacity of humans to identify odors in mixtures. Physiol Behav. 1989;46:809-14.

75. Laing DG, Link C, Jinks AL, Hutchinson I. The limited capacity of humans to identify the components of taste mixtures and taste-odour mixtures. Perception. 2002:31:617-35.

76. Marshall K, Laing DG, Jinks AL, Hutchinson I. The capacity of humans to identify components in complex odor-taste mixtures. Chem Senses. 2006;31:539-45.

77. Gray WB. "Enter Sandman" with Cab? Road testing Smith's theories. SFGate; 2007. [http://www.sfgate.com/wine/article/Enter-Sandman-with-Cab-Roadtesting-Smith-s-3235605.php]. Accessed 13 August 2015.

78. Chiou R, Rich AN. Cross-modality correspondence between pitch and spatial location modulates attentional orienting. Perception. 2012;41:339-53.
79. Klapetek A, Ngo MK, Spence C. Do crossmodal correspondences enhance the facilitatory effect of auditory cues on visual search? Atten Percept Psychophys. 2012;74:1154-67.

80. Berlioz H. A treatise on modern instrumentation and orchestration, dedicated to Frederick William IV, King of Prussia. London: Novello; 1855.

81. Spence C. Music from the kitchen. Flavour. 2015;4:25.

82. van Ee R, van Boxtel JJA, Parker AL, Alais D. Multimodal congruency as a mechanism for wilful control over perceptual awareness. J Neurosci. 2009; 29:11641-9.

83. Spence C, Deroy O. How automatic are crossmodal correspondences? Conscious Cogn. 2013;22:245-60

84. Wesson DW, Wilson DA. Smelling sounds: olfactory-auditory sensory convergence in the olfactory tubercle. J Neurosci. 2010;30:3013-21.

85. Wesson DW, Wilson DA. Sniffing out the contributions of the olfactory tubercle to the sense of smell: hedonics, sensory integration, and more? Neurosci Biobehav Rev. 2011;35:655-68.

86. Konečni VJ. Does music induce emotion? A theoretical and methodological analysis. Psychol Aesthet Creat Arts. 2008;2:115-29.

87. Antin C. What does wine sound like? Punch; 2014. [http://punchdrink.com/ articles/what-does-wine-sound-like/]. Accessed 6 August 2014.

88. Köster EP, Mojet J. From mood to food and from food to mood: a psychological perspective on the measurement of food-related emotions in consumer research. Food Res Int. 2015;76:180-91.

89. Macht $\mathrm{M}$, Roth $\mathrm{S}$, Ellgring $\mathrm{H}$. Chocolate eating in healthy men during experimentally induced sadness and joy. Appetite. 2002;39:147-58.

90. Pollatos O, Kopietz R, Linn J, Albrecht J, Sakar V, Anzinger A, et al. Emotional stimulation alters olfactory sensitivity and odor judgment. Chem Senses. 2007;32:583-9.

91. Heath TP, Melichar JK, Nutt DJ, Donaldson LF. Human taste thresholds are modulated by serotonin and noradrenaline. J Neurosci. 2006;26:12664-71.

92. Smith K. Mood makes food taste different. Nature; 2006. [http://www.nature. com/news/2006/061204/full/news061204-5.html]. Accessed 27 July 2015.

93. Frandsen LW, Dijksterhui GB, Brockhoff PB, Nielsen JH, Martens M. Feelings as a basis for discrimination: comparison of a modified authenticity test with the same-different test for slightly different types of milk. Food Qual Pref. 2007;18:97-105.

94. Dess NK, Edelheit D. The bitter with the sweet: the taste/stress/temperament nexus. Biol Psychol. 1998:48:103-19.

95. Chen D, Dalton $P$. The effect of emotion and personality on olfactory perception. Chem Senses. 2005;30:345-51.

96. Bachorik JP, Bangert M, Loui P, Lark K, Berger J, Rowe R, et al. Emotion in motion: investigating the time-course of emotional judgments of musical stimuli. Music Percept. 2009;26:355-64.

97. Crisinel A-S, Cosser S, King S, Jones R, Petrie J, Spence C. A bittersweet symphony: systematically modulating the taste of food by changing the sonic properties of the soundtrack playing in the background. Food Qual Pref. 2012;24:201-4.

98. Ferber C, Cabanac M. Influence of noise on gustatory affective ratings and preference for sweet or salt. Appetite. 1987;8:229-35.

99. Walker R. The effects of culture, environment, age, and musical training on choices of visual metaphors for sound. Percept Psychophys. 1987;42:491-502.

100. Holt-Hansen K. Taste and pitch. Percept Motor Skill. 1968;27:59-68.

101. Holt-Hansen K. Extraordinary experiences during cross-modal perception. Percept Motor Skill. 1976;43:1023-7.

102. King J. Krug champagne redefines tasting notes with orchestra event. Luxury Daily; 2014. [http://www.naurucondos.com/krug-champagne-redefines-tastingnotes-with-orchestra-event/]. Accessed 6 August 2015

103. Mesz B, Trevisan M, Sigman M. The taste of music. Perception. 2011;40:209-19.

104. Bartoshuk L. Separate worlds of taste. Psychol Today. 1980;14:48-9. 51, 54-6, 63.

105. Smith BC. Is a sip worth a thousand words? The World of Fine Wine. 2008; 21:114-9. 